\title{
Fatal Outcome after Inadvertent Injection of Epinephrine Intended for Topical Use
}

Contributions to this column are prepared by the Institute for Safe Medication Practices Canada (ISMP Canada), a key partner in the Canadian Medication Incident and Prevention System. From time to time, ISMP Canada invites others to share learning based on local initiatives. The article presented here is reprinted, with permission, from the ISMP Canada Safety Bulletin 2009;9(2):1-3.

\section{INTRODUCTION}

Cour years ago, the ISMP Canada Safety Bulletin highlighted a

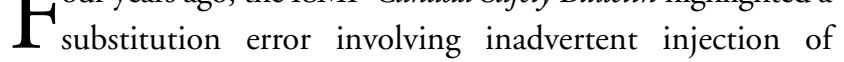
epinephrine $1 \mathrm{mg} / \mathrm{mL}$ (epinephrine 1:1,000) intended for topical application during an elective, outpatient ENT (ear, nose, throat) procedure. ${ }^{1}$ Recently, a similar incident with different underlying circumstances led to the death of a patient. The reporting hospital for the more recent incident has since implemented enhancements to its medication-use system. This bulletin was developed collaboratively as a call to action.

\section{MEDICATION INCIDENT}

During a day surgery ENT procedure, the surgeon requested local anesthetic for injection (specifically lidocaine $1 \%$ with epinephrine 1:100,000) and was handed a pre-drawn syringe. The surgeon injected the medication into the surgical site. Immediately afterward, the patient experienced a cardiac arrhythmia leading to cardiac arrest. Despite full resuscitation measures, the patient died.

Information gathered after the incident indicated that the syringe contained epinephrine $1 \mathrm{mg} / \mathrm{mL}(1: 1,000)$ intended for topical use, rather than the local anesthetic for injection that was requested. The facility subsequently contacted ISMP Canada for information about strategies to improve its medication-use system, with the ultimate goal of preventing recurrences of this problem. ISMP Canada shared a number of resources with the facility, including the Operating Room Medication Safety Checklist. As a result of working with the hospital to understand the underlying circumstances in this case, ISMP Canada updated the checklist (please see sidebar) to include targeted strategies for preventing similar incidents.

\section{NEW: Version 2 of the Operating Room Medication Safety Checklist ${ }^{\circledR}$}

ISMP Canada is pleased to announce the release of Version 2 of the Operating Room Medication Safety Checklist. This checklist facilitates knowledge translation of medication safety principles into operating room (OR) practices.

The OR medication safety checklist has been developed by ISMP Canada in collaboration with the Canadian Anesthesiologists' Society, the Operating Room Nurses Association of Canada, and ISMP (US).

The Operating Room Medication Safety Checklist complements the Medication Safety Self-Assessment ${ }^{\circledR}$ (MSSA) for Hospitals and represents a standardized approach to identifying opportunities for medication safety enhancements in the OR. The checklist is a web-based program whereby results from an individual facility can be compared with the aggregate results of other respondents both nationally and regionally. The program supports evaluation of ongoing improvement efforts over time.

More information is available from:

https://www.ismp-canada.org/operatingroomchecklist/

\section{CONTRIBUTING FACTORS}

This case differs in several important ways from the case described in the 2004 bulletin. ${ }^{1}$ In the earlier case, the topical and injectable medications had each been placed in a small, open glass container, and a substitution error had occurred. In the case described in the current bulletin, the epinephrine had been drawn into a syringe and was later mistaken for the local anesthetic to be injected. 


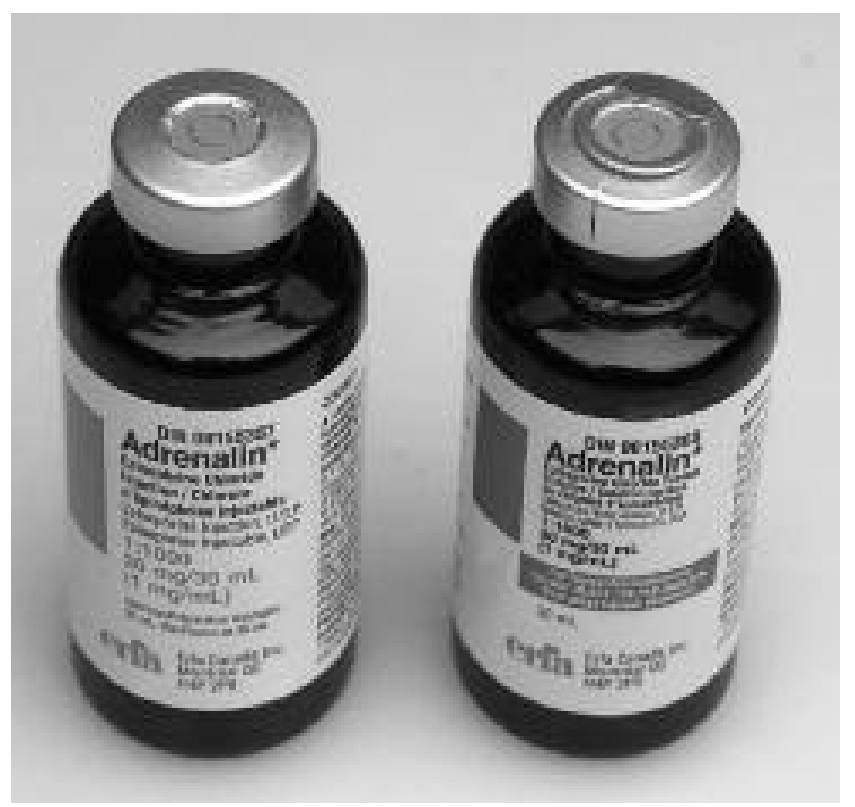

Figure 1. An example of $30 \mathrm{~mL}$ vials of epinephrine $1 \mathrm{mg} / \mathrm{mL}$ $(1: 1,000)$ currently available in Canada. Both the product intended for injection (left [vertical bar in blue]) and that intended for topical use (right [vertical and horizontal bars in red]) have a rubber stopper held in place by a metal ferrule. The topical product has a tab which, when pulled, is intended to remove the metal ferrule, yielding a "pour-bottle" format.

Several factors may have contributed to this incident:

- Epinephrine $1 \mathrm{mg} / \mathrm{mL}$ for topical use was on back order, so epinephrine $1 \mathrm{mg} / \mathrm{mL}$ for injection was made available for use in the operating room (OR). As a result, the nurse used a needle and syringe to withdraw the contents from the vial, rather than directly pouring the epinephrine from the manufacturer's container into a sterile open container with pledgets (a type of sterile gauze packing).

- The syringe containing epinephrine $1 \mathrm{mg} / \mathrm{mL}$ was not labelled.

- Preparation for the surgery was behind schedule, and the OR nurse was interrupted after she had drawn the epinephrine $1 \mathrm{mg} / \mathrm{mL}$ into a syringe. The syringe containing the epinephrine $1 \mathrm{mg} / \mathrm{mL}$ was placed on the back table. When the surgeon requested the local anesthetic for injection, the nurse placed the syringe containing the epinephrine $1 \mathrm{mg} / \mathrm{mL}$ on the metal stand beside the OR table. However, at this point, the anesthetic solution for injection had not yet been prepared, a step that was ultimately omitted because the syringe on the metal stand was believed to contain the local anesthetic for injection.

- Both medications (the epinephrine for topical application and the local anesthetic for injection) were often prepared before the start of the procedure, by one nurse, typically in one area of the OR.

\section{RECOMMENDATIONS}

The practice of withdrawing a medication intended for topical use into a parenteral syringe poses a risk for a substitution error and/or inadvertent injection. All facilities that perform procedures requiring the use of epinephrine $1 \mathrm{mg} / \mathrm{mL}$ $(1: 1,000)$ for topical application should review their processes.

The following recommendations and considerations are provided:

- Develop distinct processes for preparing and handling epinephrine for topical application. In particular, medications such as epinephrine intended for topical application should not be placed into a parenteral syringe. Conversely, a medication intended for injection (e.g., local anesthetic) should not be placed into an open container.

- Supply epinephrine for topical use in a pour-bottle format. Additional precautionary measures will be needed to deal with back orders (e.g., having the pharmacy prepare the epinephrine in a distinct, ready-to-use pour-bottle format).

- Always label all syringes and containers. ${ }^{2}$ Sterile and preprinted labels are available to facilitate labelling in operating room areas. Discard any unlabelled syringes and containers.

- Keep local anesthetics for injection in their original vials, and withdraw such medications into a syringe (and label the syringe) immediately before use. This allows the surgeon to participate in a reliable verification process using the manufacturer's product and the syringe label.

- At the hospital where a similar event occurred a few years ago, ${ }^{1}$ the surgeons now infiltrate (i.e., inject) the surgical site with local anesthetic before scrubbing and gowning for ENT procedures. Subsequent infiltration is seldom needed, but if it is required, additional local anesthetic is withdrawn directly from the vial.

- Ensure that point-of-care communication is provided by the pharmacy when a product is changed because of a new supplier or because of a product back order.

- Do not stock the multidose vial of injectable epinephrine $1 \mathrm{mg} / \mathrm{mL}$ (a high-alert drug) in any OR.

- Ensure that the word "TOPICAL" appears on the label of any container used to hold a solution intended for topical application.

- Store and prepare medications intended for topical use in distinctly separate areas from those used for storing and preparing medications for injection.

\section{A NOTE ABOUT PACKAGING FOR MANUFACTURERS OF TOPICAL MEDICATIONS}

Various OR practitioners have brought to the attention of ISMP Canada a specific concern about packaging for topical 
medications such as epinephrine. Although these medications are manufactured for topical use, the packaging may be similar to packaging used for vials containing injectable medications, consisting of a rubber stopper held in place by a metal ferrule (see examples in Figure 1). This may lead some practitioners to use a needle and syringe to withdraw the medication before transferring it to an open container. ISMP Canada has conveyed this concern to ERFA Canada Inc., the manufacturer of epinephrine $1 \mathrm{mg} / \mathrm{mL}(1: 1,000)$ for topical application. The manufacturer has been receptive and is planning to make changes.

All manufacturers are urged to review products such as epinephrine intended for topical use to ensure that they are supplied in a format distinct from that used for medications intended for injection (in particular, the design should not lead practitioners to use a syringe to withdraw the medication from the container).

The review undertaken in writing this bulletin also revealed that some hospitals routinely supply to the OR multidose vials of epinephrine $1 \mathrm{mg} / \mathrm{mL}$ for injection, with the intention that this product be used for topical application. In some hospitals the pharmacy adds a label alerting practitioners that the product is provided "for topical use". All facilities and clinics that offer ENT surgical procedures (and any other procedure requiring epinephrine $1 \mathrm{mg} / \mathrm{mL}$ for topical use) are urged to carefully review the processes for supply and preparation of topical medications and to consider the potential risk of the type of error described in this bulletin. Distinct and separate processes are needed for preparation and handling of medications intended for topical application and those intended for injection.

\section{References}

1. Risk of tragic error continues in operating rooms. ISMP Can Saf Bull 2004[cited 2009 Jan 16];4(12):1-2. Available from: http:// www.ismp-canada.org/download/ISMPCSB2004-12.pdf
2. Errors with injectable medications: unlabelled syringes are surprisingly common! ISMP Med Saf Alert 2007[cited 2009 Feb 23];12(23): 1-2. Available from: http://www.ismp.org/newsletters/acutecare/ articles/20071115.asp

\section{Acknowledgements}

ISMP Canada gratefully acknowledges expert review of this bulletin by (in alphabetical order): Patti Cornish, RPh, BScPhm, Patient Safety Service, Sunnybrook Health Sciences Centre; Ronald Storey Fenton, MD, FRCSC, FRCS, Associate Professor, Department of Otolaryngology, Head and Neck Surgery, University of Toronto, and Otolaryngologist and Head and Neck Surgeon, St Michael's Hospital; Alex Ho, MD, FRCPC, Department of Anesthesia, St Michael's Hospital, Toronto; Jonathan C Irish, MD, MSC, FRCSC, FACS, Chief, Department of Surgical Oncology, University Health Network and Mount Sinai Hospital, and Professor, Department of Otolaryngology, Head and Neck Surgery, University of Toronto; Beverley A Orser, MD, PhD, FRCPC, Canada Research Chair in Anesthesia and Professor of Physiology and Anesthesia, University of Toronto, and Department of Anesthesia, Sunnybrook Health Sciences Centre; Susan Paparella, RN, MSN, Vice President, Institute for Safe Medication Practices (US); Kathy Radcliffe, RN, CPN $(\mathrm{C})$, Education and Development Clinician, Perioperative Services, Hamilton Health Sciences, Henderson site, and Ontario representative, Operating Room Nurses Association of Canada; John W Senders, PhD, Professor Emeritus, University of Toronto; Linda Socha, RN, BSN, CPN(C), President, Operating Room Nurses Association of Canada; Terri Stuart-McEwan, RN, BScN, MHS, Clinical Director, Surgical Program, Women's College Hospital.

Medication incidents (including near misses) can be reported to ISMP Canada in 1 of 2 ways:

- through the secure web portal at http://www.ismp-canada.org/ err_report.htm

- by telephone at 416.733 .3131 or toll-free at 1.866.544.7672 (1.866.54.ISMPC) 